\title{
User-friendly Tool for Power Flow Analysis and Distributed Generation Optimisation in Radial Distribution Networks
}

\author{
M. F. Akorede ${ }^{1,2^{*}}$, H. $\operatorname{Hizam}^{1}$, I. Aris ${ }^{1}$, M. Z. A. Ab Kadir ${ }^{1}$, and M. Hojabri ${ }^{3}$ \\ ${ }^{1}$ Department of Electrical \& Electronic Engineering, Universiti Putra Malaysia, 43400 UPM Serdang, Selangor, Malaysia. \\ ${ }^{2}$ Department of Electrical \& Electronics Engineering, University of Ilorin, 240003 Ilorin, Nigeria. \\ ${ }^{3}$ Faculty of Electrical \& Electronic Engineering, Universiti Malaysia Pahang, Pekan Campus, 26600 Pekan, Malaysia.
}

\begin{abstract}
The intent of power distribution companies (DISCOs) is to deliver electric power to their customers in an efficient and reliable manner - with minimal energy loss cost. One major way to minimise power loss on a given power system is to install distributed generation (DG) units on the distribution networks. However, to maximise benefits, it is highly crucial for a DISCO to ensure that these DG units are of optimal size and sited in the best locations on the network. This paper gives an overview of a software package developed in this study, called Power System Analysis and DG Optimisation Tool (PFADOT). The main purpose of the graphical user interface-based package is to guide a DISCO in finding the optimal size and location for DG placement in radial distribution networks. The package, which is also suitable for load flow analysis, employs the GUI feature of MATLAB. Three objective functions are formulated into a single optimisation problem and solved with fuzzy genetic algorithm to simultaneously obtain DG optimal size and location. The accuracy and reliability of the developed tool was validated using several radial test systems, and the results obtained are evaluated against the existing similar package cited in the literature, which are impressive and computationally efficient.
\end{abstract}

KEYWORDS: distribution networks, distributed generation, graphical user interface, PFADOT, fuzzy genetic algorithm, optimisation

[Received December 30 2016; Revised April 8 2017; Accepted June 1 2017]

\section{INTRODUCTION}

In the last five decades, engineering generally has felt the impact of digital computer in design and analysis of systems. The field of power systems was no exception to this development (Pai, 1979). These days, computers have become so powerful and advanced that they can easily be used to carry out some simulations in analysing large interconnected power networks (Saadat, 2002). In this wise, power system software packages can basically be categorised as commercial and educational/research purpose software (Milano, 2005). A few examples of the commercial software packages developed for solving power system analysis problems include PSS/E, ETAP, PowerWorld, PSCAD, etc.

However, the major disadvantage of these packages is that they require good modelling and simulation knowledge. In addition to this, none of them allows the user to change its source codes. On the other hand, a few non-commercial simulation tools that can be used for similar purpose are MATPOWER, Power System Analysis Toolbox (PSAT), Power System Toolbox (PST), to mention but a few. Although these packages can be used for system analysis, none of them is adequate for solving DG optimisation problems.
On the other hand, the Power Flow Analysis and DG Optimisation Tool (PFADOT) developed in this study is a highly interactive windows-based package for power system analysis and distributed generation optimisation in radial distribution networks. All the routines of the package were developed using MATLAB m-files version 7.6 (R2008a); hence it is not guaranteed that it would run on earlier MATLAB versions. The results obtained when the developed package was tested with several radial test systems were highly impressive, with high computational speed.

\section{RELATED STUDIES}

Distributed generation (DG) is defined as any source of electric power of limited capacity, which is usually connected to the power system distribution networks or the customer side of the meter, as it is connected to subtransmission networks at up to $132 \mathrm{kV}$ level in some countries (CIRED, 1999). DG technologies are divided into renewable and nonrenewable, based on the primary energy source used. Apparently, the environmental concerns of reducing the greenhouse gas emissions and the current deregulation of electric energy market are the main drivers leading to the recent renewed global interest in DG since the conventional 
power generation technology is a major contributor of air pollutants.

To attain the maximum benefits offered by DG, it is very crucial to determine the optimal size and location on a given network. Failure to do this would not only result in increase in energy loss cost to the DISCO but could also jeopardise the overall system operation. For example if the penetration level of DG in the system goes beyond a certain value, it can result in increase in the power frequency beyond the preset upper limit, which could trip off all the DG units in the network. This occurrence would certainly lead to a mismatch between the total central generation and the present system load demand. When this happens, there would be a reduction in the system frequency, even with the reaction of the central generators governors, which would send trip signals to the under-frequency relays to shut down the central generators, thereby resulting in a total system collapse due to frequency instability (Vu Van et al., 2006).

So far, to the knowledge of the authors of this paper, Voltage Stability and Optimisation (VS\&OP) package developed by Gözel et al. (2008) is the only open source package that can tackle power system analysis and DG optimisation problems. In the package, Golden Section Search and Grid Search Algorithms based on successive load flows were the optimisation techniques used. However, as good as the package could have been, it adopted minimisation of active power loss as the only factor to determine DG and capacitor placement in radial distribution networks. The approach did not constrain the capacity of DG to be penetrated into the system. It considered a DG whose size ranges from $0 \%$ to $100 \%$ of the system total load power. In finding the optimal size, a step increment of $1 \%$ of the system load demand is continuously added to the DG size, from 0 , until a value of which a further addition would begin to increase the overall system power loss. Our concern however, is that this method would present a too big DG size that could provoke power quality and protection issues on the system.

As a matter of fact, connection of optimum DG capacity to the appropriate load bus(es) on a system reduces the overall active power loss on the system in most cases. This fact made many of the earlier works (Kim et al., 1998; Griffin et al., 2000; Mithulananthan, 2004; Wang and Nehrir, 2004; Acharya et al., 2006; Kashem et al., 2006; Singh et al., 2007; Gözel and Hocaoglu, 2009; Singh and Goswami, 2009) adopt minimisation of active power loss alone to determine the optimum size and location of DG unit(s). However, our experience in the previous study shows that the use of power loss alone is not adequate to determine the optimal allocation of DG in power networks, as this could lead to incorrect results. Further analysis on the system stability, power quality, protection issues, etc, are equally essential factors to be considered in finding the optimal size and location of DG in a particular network. This missing aspect in most early works is addressed in this study.

Apart from the works referenced in the previous paragraph, several other techniques have been proposed in addressing optimisation of DG capacity and location problems. However, only a few of them are mentioned in this work, due to space constraint. An analytical approach is used by Khan and Choudhry (2010), dynamic programming (Khalesi et al., 2011), AC optimal power flow (Ochoa and Harrison, 2010). Nevertheless, most of these approaches have the problem of premature convergence and excessive computational time. Bearing this in mind, a multi-objective function that comprises three objective functions is formulated and solved using fuzzy-genetic algorithm (FGA) in this study. Details of the problem formulation, the power flow approach which is specifically peculiar to distribution networks and the FGA used as the optimisation and search technique, have been carried out and reported in our previous work, and therefore not repeated here, since the main focus of this paper is to describe the evolution of PFADOT package.

In the FGA, a fuzzy controller is integrated into simple genetic algorithm to avoid premature convergence and improve the computational speed - the bane of many optimisation techniques.

\section{OBJECTIVE FUNCTION FORMULATION}

The objectives considered in this study are maximisation of the energy loss cost savings, minimisation of line voltage drop, as well as maximisation of the power transfer capability of the system. This problem formulation has been carried out in our previous work (Akorede et al, 2014). The percentage decrease in total energy loss cost savings (ELCS) when a DG is installed and run for $\mathrm{T}_{d}$ hours in a day is as given in eqn (1). It is desired to have a DG size that maximises this objective function when located at a particular bus.

$$
(\text { ELCS })=\frac{C_{E} \sum_{m=1}^{\mathrm{N}-1} T_{d}\left(P_{L m}{ }^{B}-P_{L m}{ }^{D G}\right)}{C_{E} \sum_{m=1}^{\mathrm{N}-1} T_{d} P_{L m}{ }^{B}}
$$

subject to eqn (2).

$$
\mathrm{O} \leq \sum_{m=1}^{N-1} P_{L m}{ }^{D G}<\sum_{m=1}^{N-1} P_{L m}{ }^{B}
$$

where $C_{E}$ is unit energy cost $(\$ / M W h), P_{L m}{ }^{B}$ and $P_{L m}{ }^{D G}$ are line $m$ active power loss before and with $\mathrm{DG}$ installation respectively, and $\mathrm{N}$ is the number of buses.

To improve the voltage profile of all buses, it is essential to minimise the voltage drop on all lines of the network. According to Verbic et al. (2006), the total voltage drops on the system, which is a sum of the voltage drop on all the lines of the power prior to DG connection, is presented in eqn (3), where $m$ is the line number. $\Delta \mathrm{V}_{\mathrm{m}}, \mathrm{R}_{\mathrm{m}}$, and $\mathrm{X}_{\mathrm{m}}$ are voltage drop, resistance, and reactance of line $m$ respectively.

$$
\sum_{m}^{N-1} \Delta V_{m}=\sum_{m}^{N-1} \sqrt{\frac{P_{L m}\left(R_{m}{ }^{2}+X_{m}{ }^{2}\right)}{R_{m}}}
$$

Minimising the line voltage drop (LVD) is synonymous to maximising the difference between the voltage drop on the line before and after DG connection to the network. This can be formulated in percentage form as in given in eqn (4). In 
other words, the highest value of the expression on the RHS of eqn (4) minimises the LVD.

$$
\min (L V D)=\max \left(\frac{\sum_{m=1}^{N-1} \Delta V_{m}{ }^{B}-\sum_{m=1}^{N-1} \Delta V_{m}{ }^{D G}}{\sum_{m=1}^{N-1} \Delta V_{m}{ }^{B}}\right)
$$

The power transfer capability (PTC) of a power system is the maximum power that can be transported via a power line from one point to another, without compromising the system security. DG is a viable alternative to distribution system expansion in response to the ever-increasing population growth since environmental and economic constraints prohibit expansion of the existing network. The overall PTC of a distribution system could be computed from eqn (5), which is the sum of all the power transported on a line $m$, when $P_{D G}$ size is connected to bus $B_{k}$.

$$
\max (P T C)=\frac{\left(P_{D G} B_{k}-\sum_{m=1}^{N-1} P_{L m}{ }^{D G}+\sum_{m=1}^{N-1} P_{L m}{ }^{B}\right)}{P_{s w}-\sum_{m=1}^{N-1} P_{L m}{ }^{B}}
$$

Subject to the bus voltage, line thermal limit and DG capacity constraints presented in eqn (6).

$\left|V_{i}\right|_{\min } \leq\left|V_{i}\right| \leq\left|V_{i}\right|_{\max } S_{m} \leq S_{m}^{\max }$ and $P_{D G} \leq 0.4 \sum_{i=1}^{N} P_{D i}$

The DG size is limited to $40 \%$ of the total power demand of the system to avoid power quality and protection issues, which might arise as DG size increases. Combining these individual objectives yields the expression presented in eqn (7). In other words, the bus $B_{k}$ that maximises the objfun when $P_{D G}$ is sited there is regarded the optimal location in this study.

$$
\text { objun }_{k}=\max \left(W_{1} E L C S+W_{3} P T C\right)+\min \left(W_{2} L V D\right)
$$

Where the weighting factors $\mathrm{W}_{1}+\mathrm{W}_{2}+\mathrm{W}_{3}=1$. These weights are allocated by the planner to indicate the relative importance of each objective. In this work, $0.4,0.3$ and 0.3 are respectively used for $\mathrm{W}_{1}, \mathrm{~W}_{2}$ and $\mathrm{W}_{3}$.

\section{DG PLACEMENT ALGORITHM}

The DG placement algorithm flowchart is presented in Table 1. The algorithm uses genetic algorithm (GA) to solve the optimisation problem formulated in eqn (7). GA is a stochastic search and optimisation technique based on the mechanism of natural selection and natural genetics search. Details of the fuzzy genetic algorithm used in this paper have been described previously.
Table 1: Power Flow and DG Optimization Algorithm.

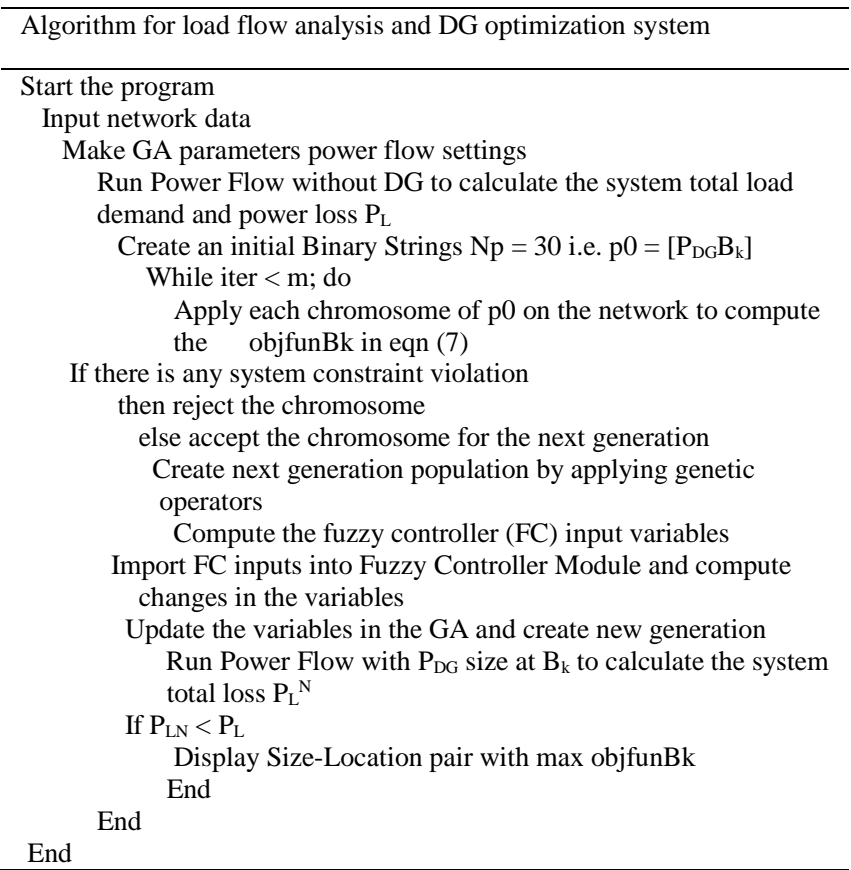

Selection of appropriate GA control parameters is described as a complex optimisation problem (Srinivas and Patnaik, 1994), which requires a maximum caution. The reason for this is that the performance of GA is largely dependent on these parameters. In addressing this issue, the two distinct parameter sets identified to guarantee good performance (Srinivas and Patnaik, 1994) are implemented in this study. The GA convergence plots for the two cases are displayed in Figure 1. From the figure, it is clear that Case 1 converges faster than Case 2, and therefore adopted in this study.

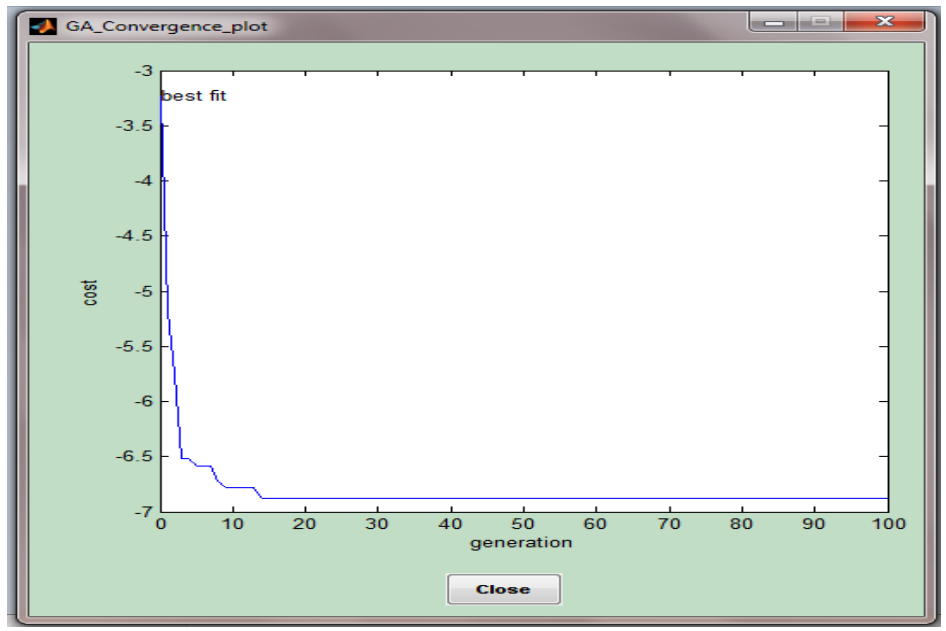

(a) Case 1 


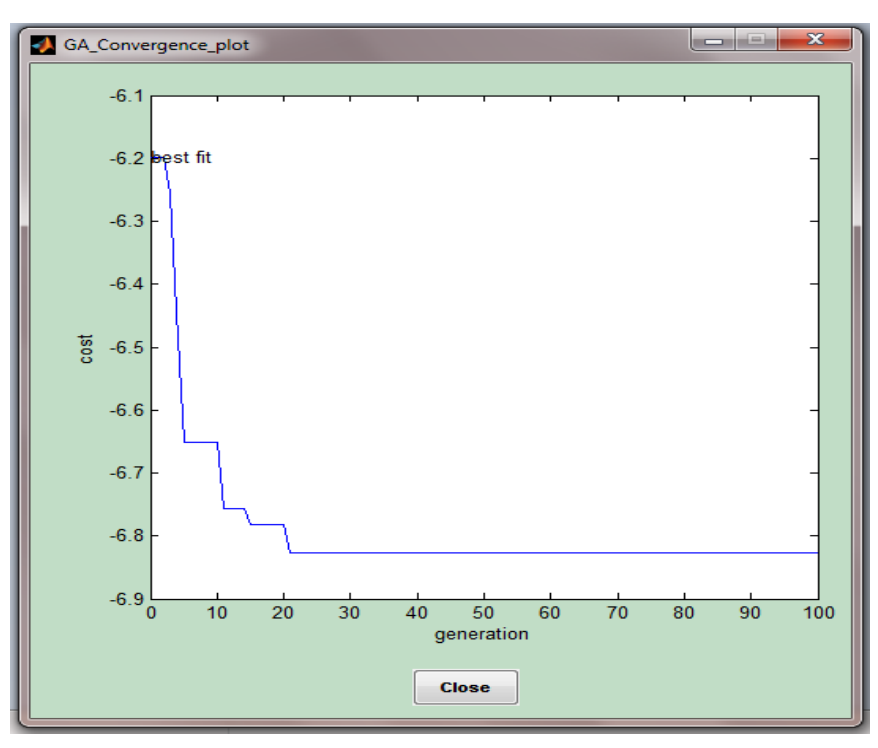

(b) Case 2

Figure 1: GA Convergence Plots.

\section{SOFTWARE DEVELOPMENT PROCEDURE}

A graphical user interface (GUI) is a graphical display that contains devices/components, which enables a user to perform interactive tasks on a computer system, without the user having to create a script or type commands at the command line. It is an interface between a user and a computer system (Hanselman and Littlefield, 2005). Each component, and the GUI itself, are associated with one or more user-written routines known as callbacks. The execution of each callback is triggered by a particular user action such as a button push, mouse click, selection of a menu item, or the cursor passing over a component. This section gives brief explanations on the procedure followed in this study to develop PFADOT software package using the GUI feature of MATLAB. The areas summarily covered include designing a GUI, starting GUIDE, adding components to a GUI, and GUI programming.

\section{A. Designing a GUI}

Visual composition and temporal behaviour of GUI design is an essential part of software application programming. Its goal is to enhance the efficiency and ease of use for the underlying logical design of a stored program. Before creating the actual GUI, it is important to decide what operations GUI is to perform and how it is desired to work. Usually, it is helpful to draw the GUI layout on a piece of paper and envision the user interface (User, 2011). This layout sketch would contain a visual representation that is well tailored to the tasks the user wishes it to perform when the software package is fully developed. Good user interface design facilitates finishing the task at hand. In this study, the user interface design is carried out with the intent to making the user's interaction as simple and efficient as possible, in terms of accomplishing the user's goals.

\section{B. Starting GUIDE}

GUIDE is the MATLAB GUI development environment, which provides a set of tools for creating graphical user interfaces (GUIs) (GUIDE, 2010b). These tools simplify the process of laying out and programming GUIs. Guide initiates the GUI tools that allow the software developer to create or edit GUIs interactively. There are many ways to start GUIDE. The approach used in this study is by typing guide at the command line of MATLAB, which displays the GUIDE Quick Start dialog box shown in Figure 2.

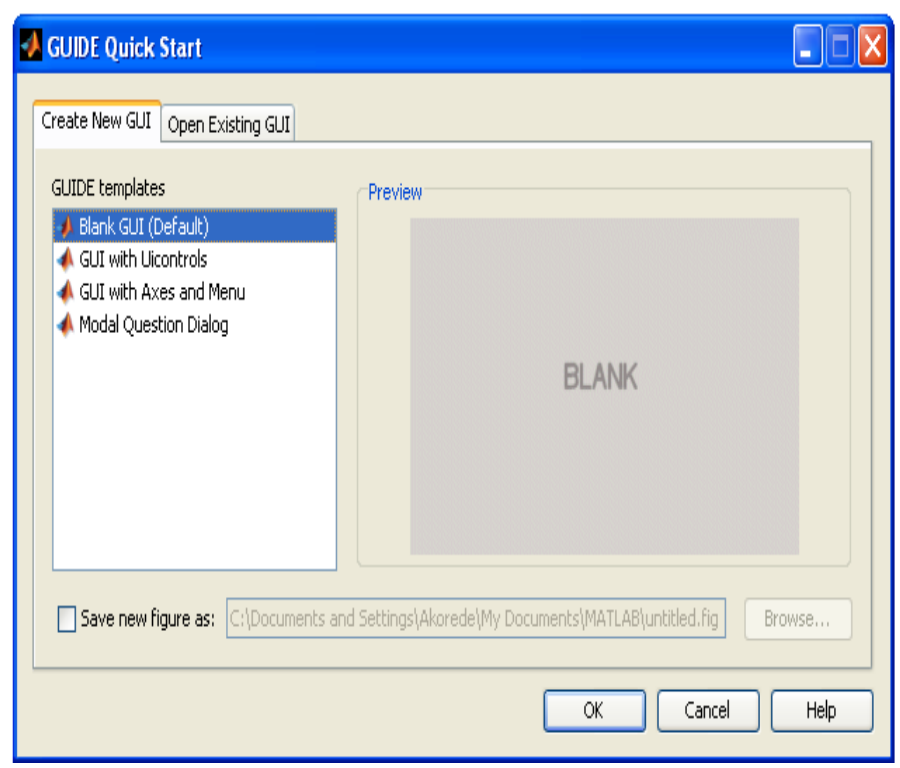

Figure 2: GUIDE Quick Start Dialog Box.

As could be seen in the figure, the GUIDE Quick Start dialog box contains two tabs

I. Create New GUI Tab - which enables the software developer to create a new GUI by choosing one of the provided templates. The name by which the GUI could be saved can also be specified here, when the check box on Figure 2 is checked. This approach was employed in this study.

II. Open Existing GUI Tab - here one can choose to open a previously created GUI in GUIDE. This is done by choosing a GUI from the current directory or browsing other directories.

\section{Adding Components to a GUI}

Using the GUIDE Layout Editor, GUI is populated by clicking and dragging GUI components - such as buttons, text fields, sliders, axes, and so on - from the component palette at the left side of the Layout Editor into the layout area. A blank GUI template displayed in the Layout Editor is shown in Figure 3 (GUIDE, 2010b). Menus, context menus, and a toolbar for the GUI could as well be created here. Thereafter, the Property Inspector was opened to set the properties such as tag name, font name, font size, 
background/foreground colour, relative position, etc. of each component.

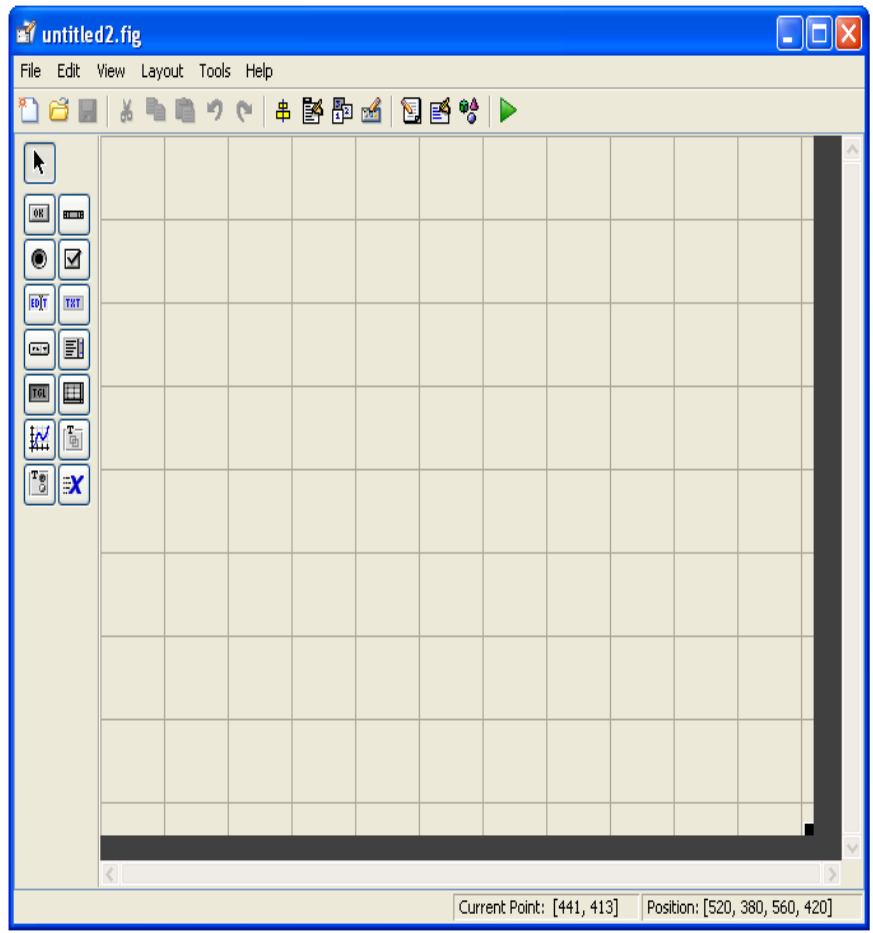

Figure 3: Blank GUI Template Displayed in the Layout Editor.

\section{Programming a GUI}

Saving GUI layouts such as the one presented in Figure 3, creates two files: a FIG-file with fig extension that contains the GUI layout, and an M-file with $m$ extension, which contains the code that controls the GUI (User, 2011). In this study, PFADOT.fig and PFADOT.m are respectively generated when the GUI layout was saved using PFADOT as the filename. The M-file is used to control how the GUI works. It provides code to initialize the GUI and contains a framework for the GUI callbacks. Callbacks are the routines that execute in response to user-generated events such as a mouse click. Using the M-file editor, PFADOT codes were written for the callbacks to perform the functions of each intended task.

\section{E. Software Development Process Limitation}

In an attempt to reduce the software development failure rate, various risk factors have been identified by software engineering and information systems researchers (Jiang and Klein, 2000). These include non-existent users, multiple users, inability to specify purpose or usage, technical complexity, project size, etc. However, since the developed software in this study is user-specific, i.e. meant for a user that is technically informed in the field, it is not affected by these risk factors. It is highly user-friendly, and so no risk or error control measure is required in the process. The limitation of PFADOT package however, is that it is not designed to handle a system with more than 99 buses, due to space constraint on the plot axes; it can carry out load flow analysis of a system with up to 120 buses though. Another limitation of the developed package is that it cannot run on MATLAB versions earlier than 7.6 (R2008a).

\section{SOFTWARE DESCRIPTIONS}

The Power Flow Analysis and DG Optimisation Tool (PFADOT) developed in this study is a package of MATLAB $\mathrm{m}$-files for solving power flow and DG optimisation problems in radial distribution systems. It is installed in MATLAB by setting the PhD_PFADOT folder to MATLAB path. Thereafter, the package can be launched from MATLAB prompt as follows: >> PFADOT, and strike the keyboard Enter button. This will open the main user interface window of the package as depicted in Figure 4. All other computational operations could be launched from this window by means of pushbuttons, menus and/or shortcuts. The main window, which carries the Universiti Putra Malaysia logo, comprises three major sections, namely System Activation, Power Flow Analysis, and DG Optimisation sections.

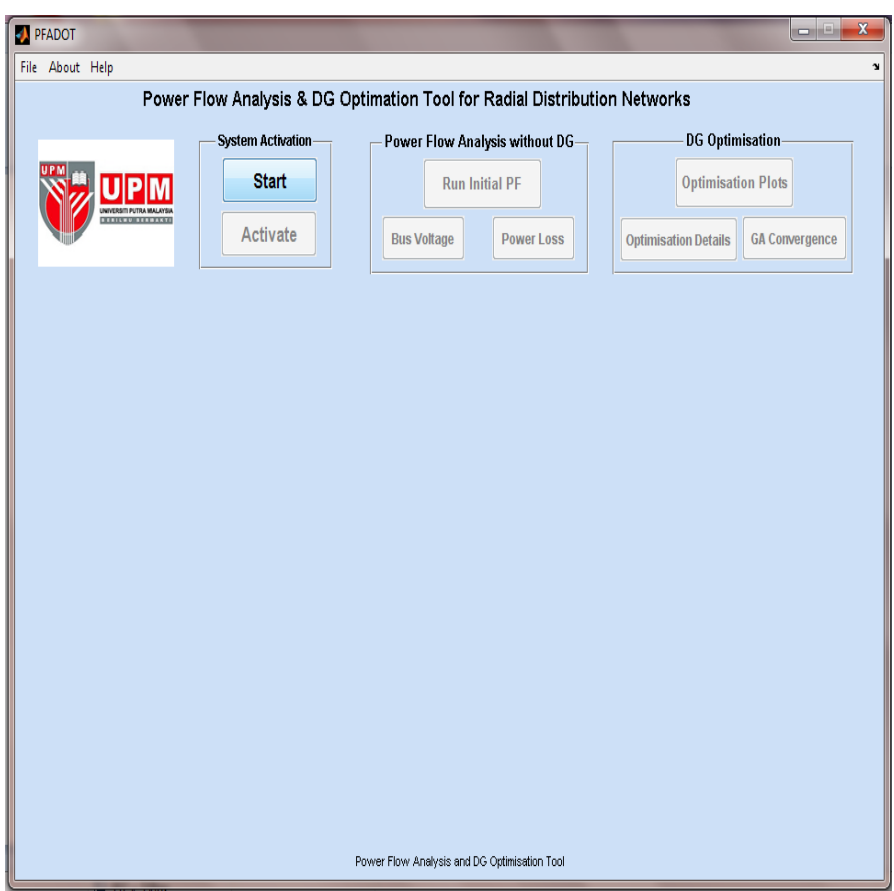

Figure 4: PFADOT Main User Interface Window.

The System Activation initially consists of the 'Start' and 'Activation' buttons. When the 'Start' button is pressed, it changes to 'Reset' button and then takes the user to the data entry window, as displayed in Figure 5. The 'Activate' button is pressed after the system data have been typed or loaded into the appropriate text boxes and the 'Run Initial PF' button is enabled to prepare the package for power flow analysis at basecase, without DG on the system. Here, the results of the line power loss and bus voltage of the system could be viewed. DG optimisation section could be run only when the initial power flow has been carried out. In the section, the 
objective function and the power loss, as well as the fuzzy genetic algorithm convergence plots could be displayed

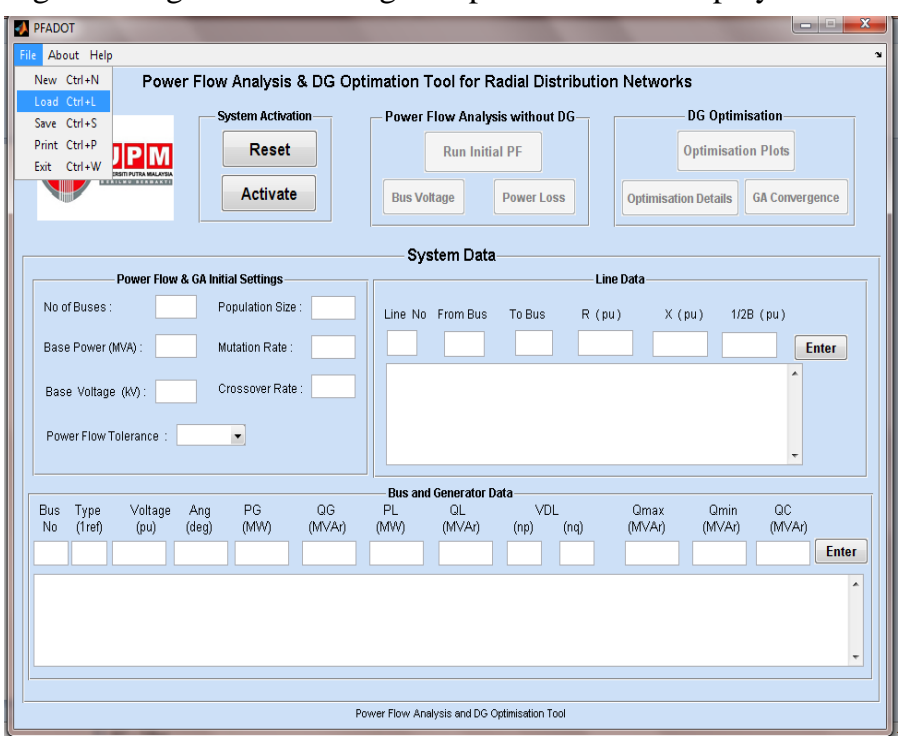

Figure 5: System Data Entry Window.

Other submenus on the main window include New, Print, and Exit; each of these has a shortcut. New is required when the user intends to clear the loaded data and wants to manually input new file data. On the other hand, Print submenu opens a PrintPreview dialog box, which prompts the user to make any necessary print property modifications before printing the current window display. Exit closes the user interface but provokes a dialog box to ask the user if he really wishes to close the application.

Data Entry: Data entry is handled via the System Data interface. Here, the power flow and GA initial settings, line data, as well as bus and generator data could be manually typed into the provided text boxes. The Enter button on the line data is required to be depressed for each entry in order that the package accepts it as a valid entry. This equally applies to that on the bus and generator data unit. When all the required system data have been entered, it is essential for the user to save it as a text file with a filename and $d s f$ extension, for future reference. This is done using the Save submenu that prompts the data file save dialog box shown in Figure 6 . The saved file can later be retrieved by using the Load submenu as shown in Figure 5. The Load File dialog box appears as shown in Figure 7, and the user clicks on the open to load a file.

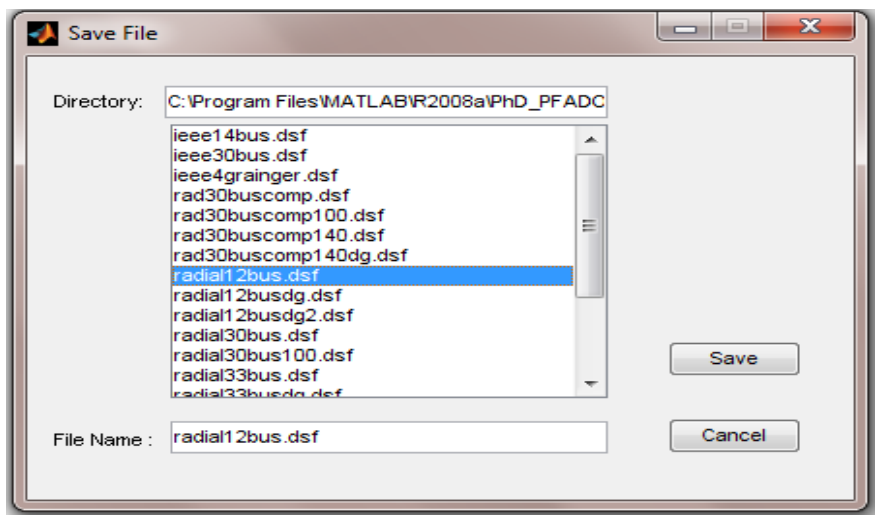

Figure 6: Save Data File Dialog Box.

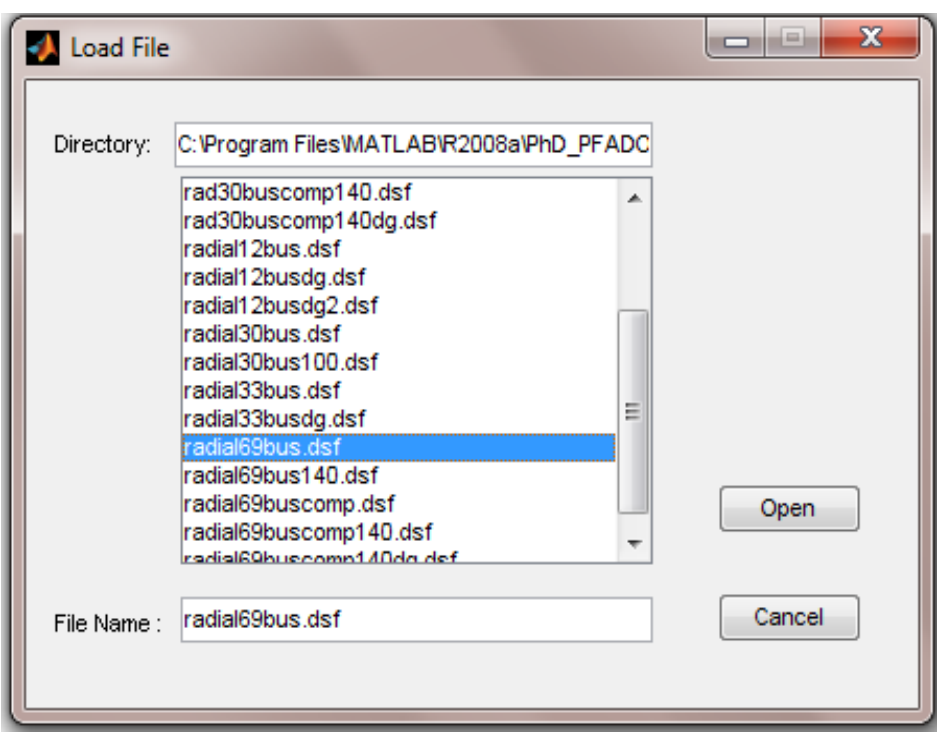

Figure 7: Data File Loading Dialog Box.

The alternative way a system data could be managed is for the user to load a pre-stored file data from a storage device. However, the pre-stored file must be in IEEE common format, with the extension $d s f$. Other data formats are required to be converted to this format. Figure 8 depicts a loaded file data into the appropriate text boxes. Meanwhile in entering the data manually, it is essential for the user to be acquainted with the type of data required in each text box. For example, 0,1 or 2 is required for 'Type' column on the Bus and Generator Data unit. 0 is input for a load bus, 1 for a reference bus and 2 for a PV bus. Columns 9 and 10 are for

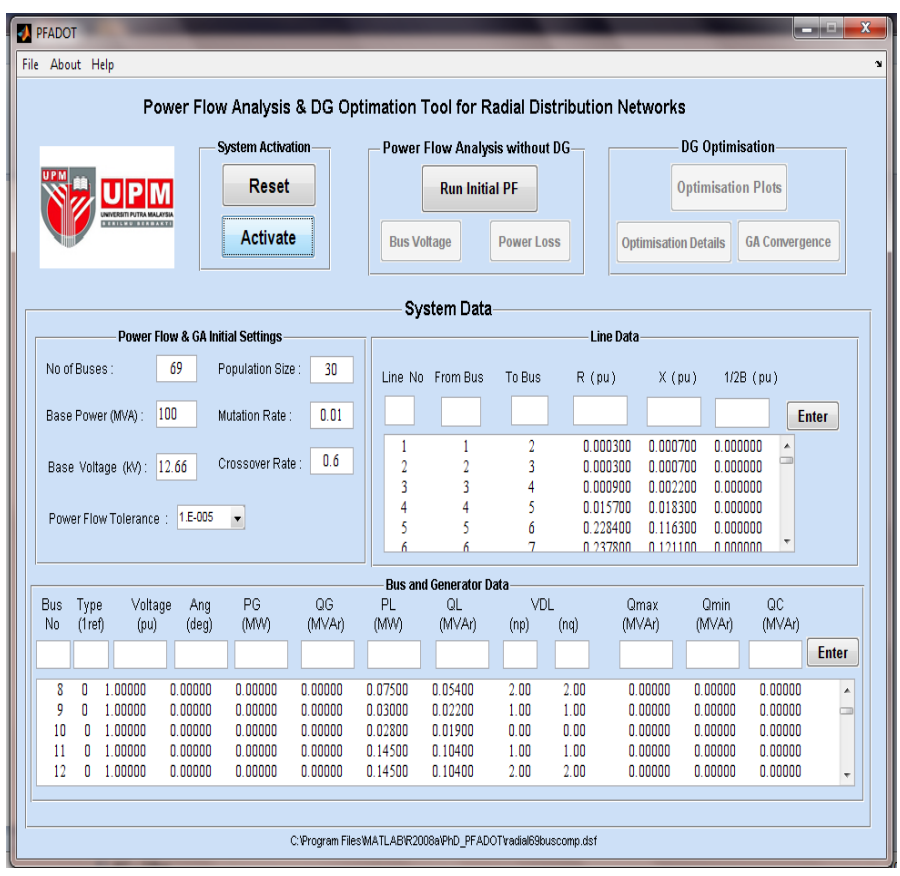

Figure 8: Loaded File Data Window. 
voltage dependent loads. $n p$ and $n q$ are the load active and reactive power exponents respectively, where 0,1 or 2 is also used. 0 is input for constant power loads, 1 for constant current loads and 2 for constant impedance loads. This load modelling is essential for accurate and representative results to be obtained in distribution systems.

To make the developed package more user friendly, the GA initial settings are deleted from the main user interface after the optimal control parameters settings have been obtained. The resulting interface is as shown in Figure 9. However, the optimised parameters settings have been embedded in the programme, which now runs behind the scene. This is done to avoid the complexity of GA settings which the system operator, who might not be informed about GA, could be facing in operating the PFADOT package.

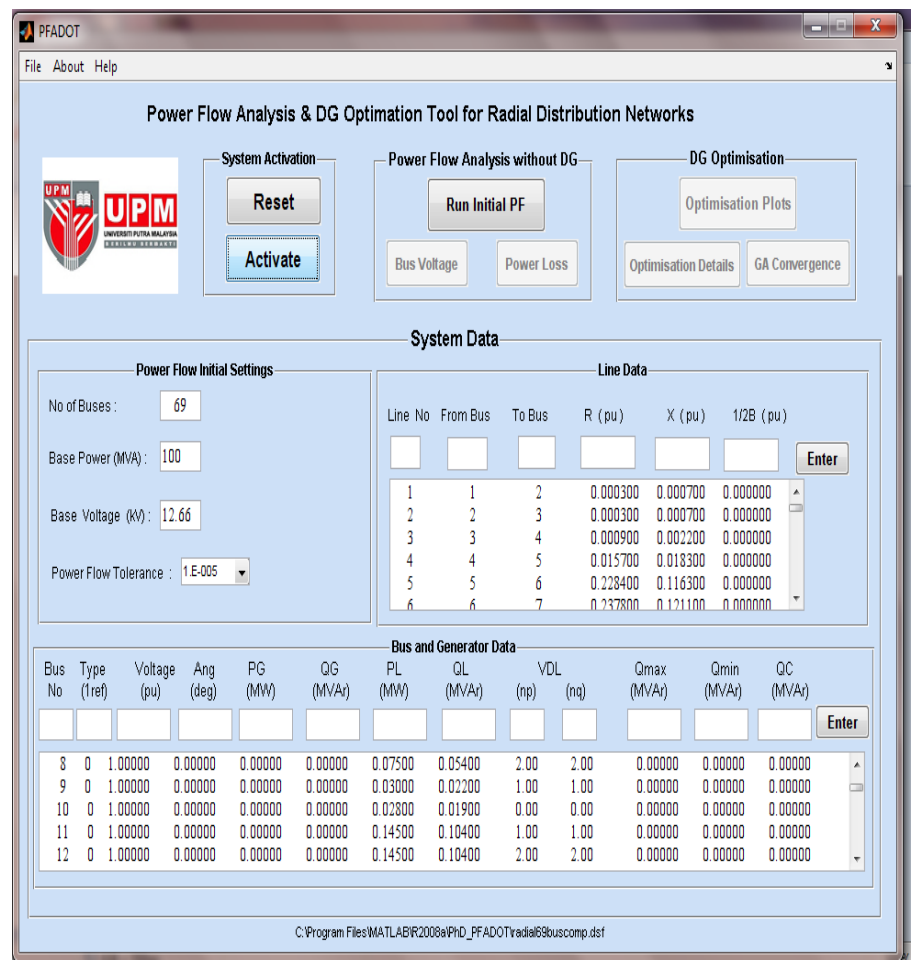

Figure 9: User-Friendly Data Entry Window.

\section{RESULTS AND DISCUSSION}

To test the accuracy and reliability of the developed PFADOT package, several distribution test systems are employed. However, due to brevity of space, only a few results are presented and discussed in this paper. The power flow and bus voltage results before DG connection, as well as the objective function and power loss plots with DG are not shown for 12-bus and 30-bus systems. The case study test systems data are presented in the Appendix.

\section{A. Case Study I-12-Bus System}

Figure 10 presents the optimisation details and the economic benefit results arising from DG installation on a 12bus radial system using the developed package. It is visible in the figure that bus 10 is the optimal location with an optimal
DG size of $0.174 \mathrm{MW}$. This is against $0.2349 \mathrm{MW}$ of DG size at bus 9 obtained in (Gözel et al., 2008) using the grid search algorithm. The reason for this disparity is that (Gözel et al., 2008) did not constrain DG size in their problem formulation, which in turn determines the location. We wish to categorically state here that this size, which is more than 50 $\%$ of the total system load demand, would provoke power quality and system protection issues when further analysis is carried out, based on our previous experience.

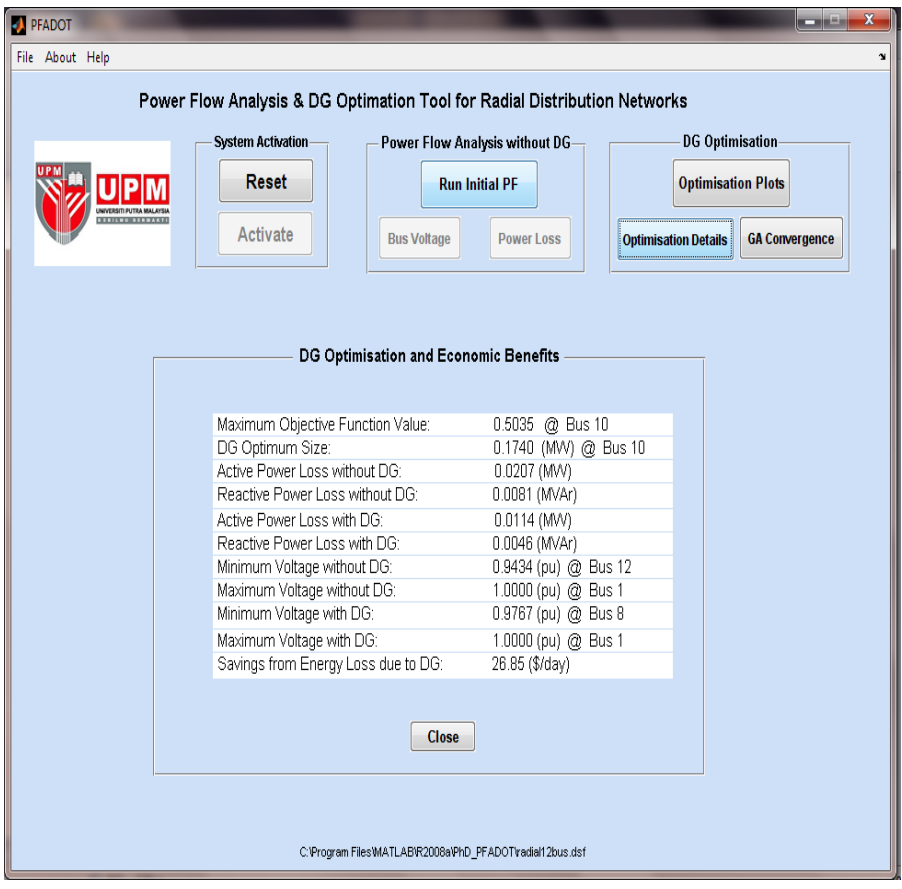

Figure 10: DG Optimisation Details of a 12-bus System.

\section{B. Case Study II-30-Bus System}

Using the developed package for this test system, 3.4865 MW of DG is recommended to be installed at bus 23 , where the objective function is maximised as shown in Figure 11.

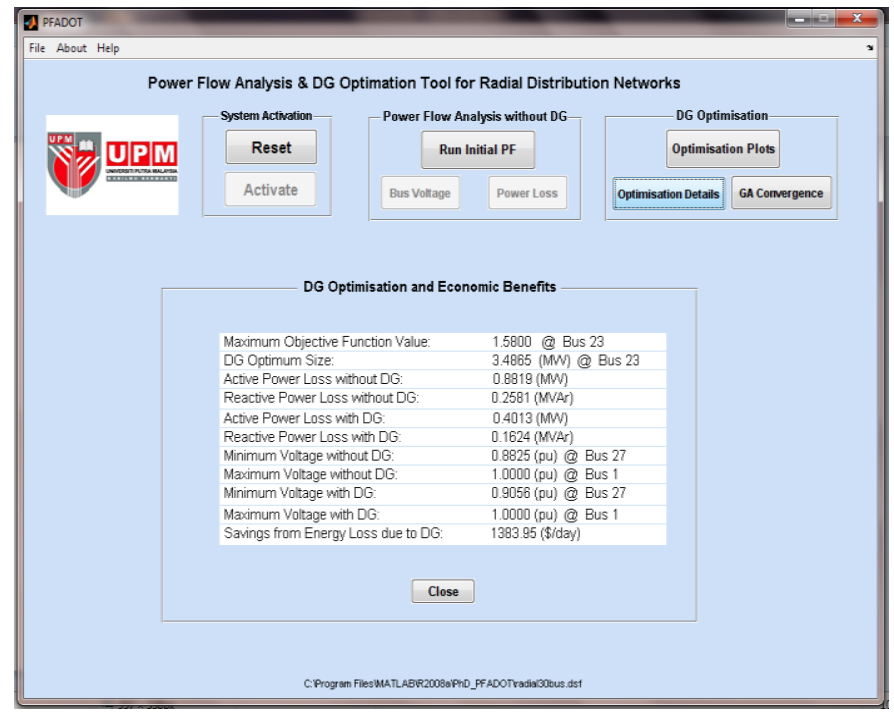

Figure 11: DG Optimisation Details of a 30-bus System. 
Adopting this recommendation would save the DISCO the sum of US $\$ 1,3833.95$ per day, based on a unit energy cost of $\$ 120$ per MWh (California, 2010).

\section{Case Study III-69-Bus System}

The power flow and line losses results at basecase are displayed in Figure 12, where the load flow algorithm converged in 4 secs. Similarly, Figure 13 shows the voltage profile of the system. The objective function and power loss plots with DG on the system with all loads modelled

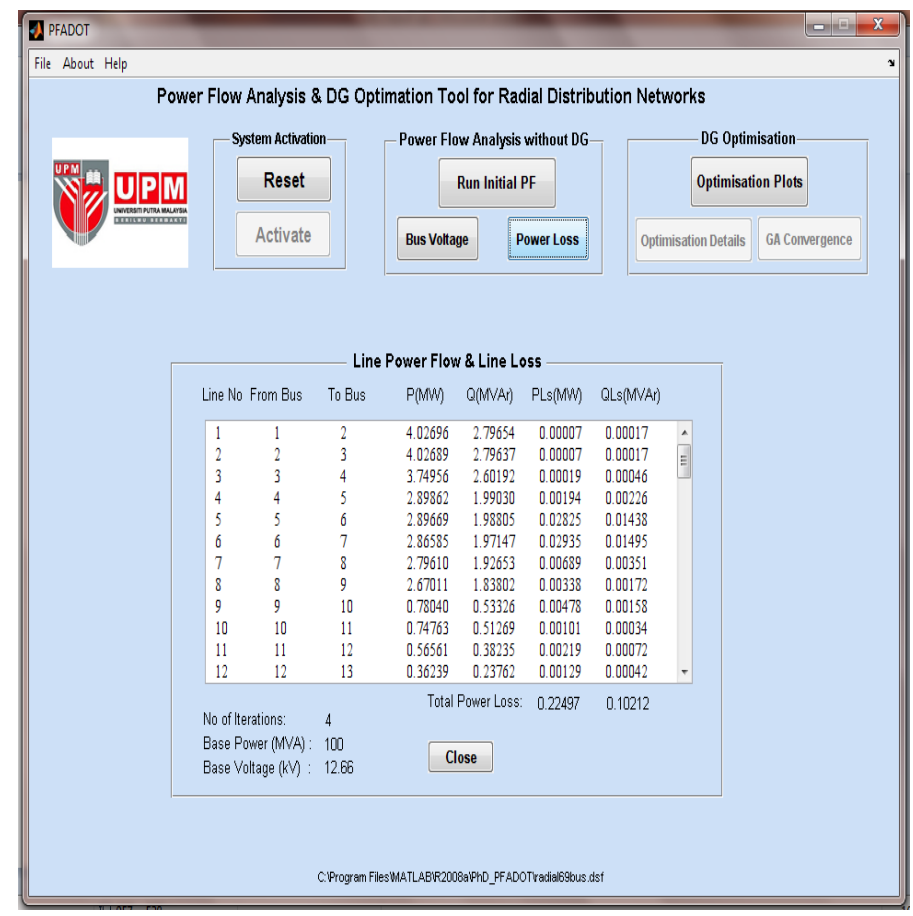

Figure 12: Power Flow Results for the Basecase 69-bus System.

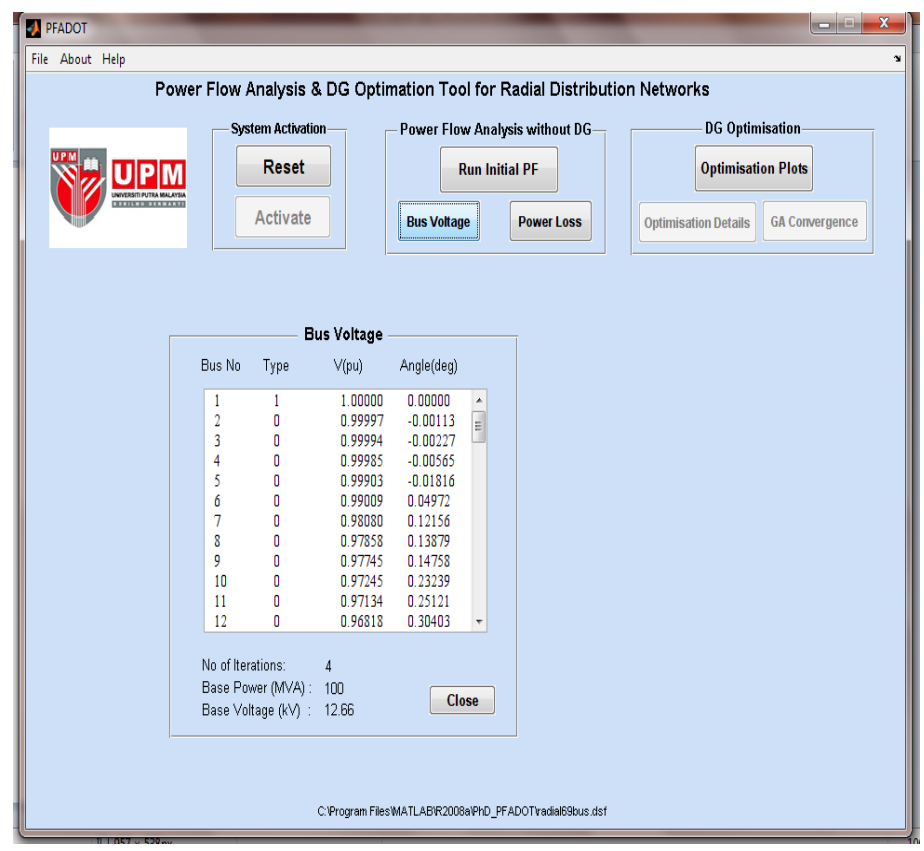

Figure 13: Bus Voltage for the Basecase 69-Bus System. as constant power are shown in Figure 14 and DG optimisation details for the same test system are presented in Figure 15. The optimal bus 61 obtained here is same for that obtained in (Gözel et al., 2008). The plot at bus1 on Figure 14 is that of the basecase without DG, since generator buses are not recommended for DG connection. It should be noted from the figure that siting DG at buses 23-27, 29-35, 37-46, and 50 would amount to a great disservice to the DISCO as the loss incurred in each of them is higher than the basecase's. They are therefore termed as critical buses where the DISCO must not attempt to place DG.

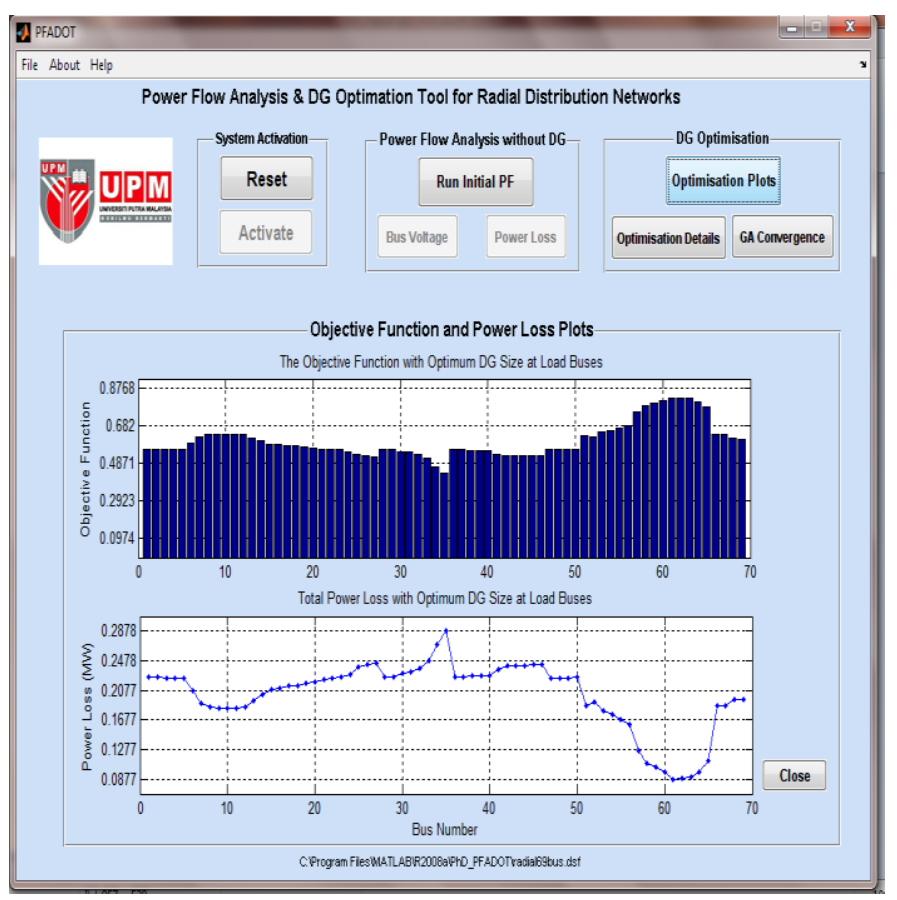

Figure 14: Basecase Objective Function and Power Loss Plots.

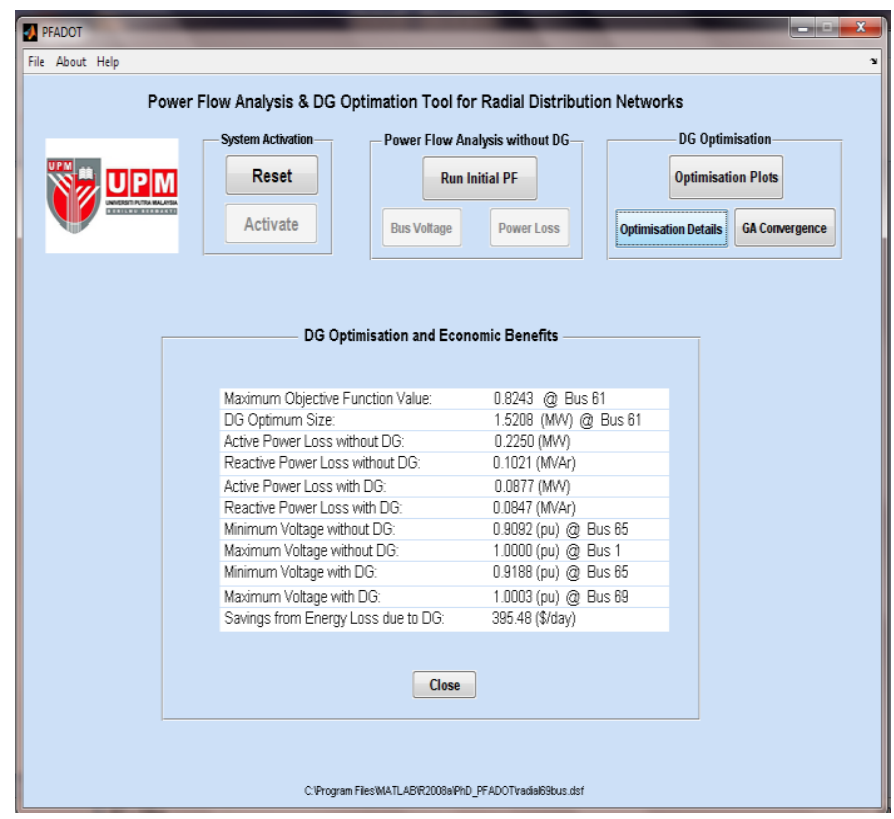

Figure 15: DG Optimisation Details for the Basecase 69-bus System. 
To reflect the voltage dependency nature of distribution systems, the loads were modelled as composite loads consisting of $46 \%$ constant power, $31 \%$ constant current and $23 \%$ constant impedance. This was run with the package and results presented in Figure 16, which really show the effect of the composite loads. Here the overall system power loss is less than when a constant power load model alone was considered for all loads.

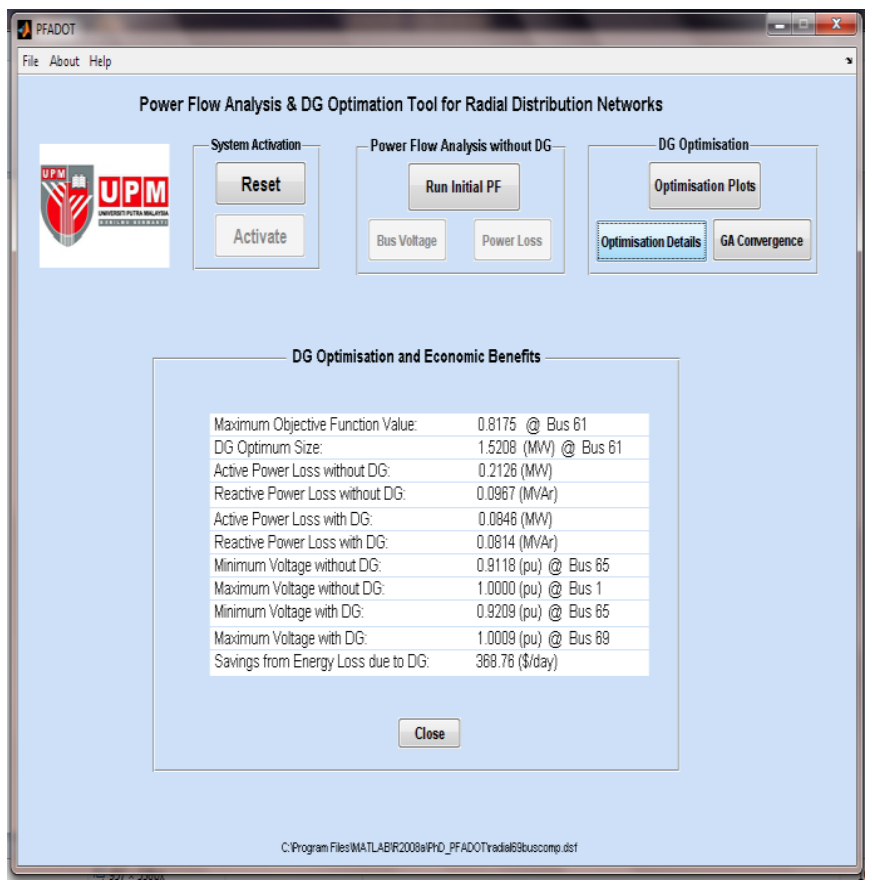

Figure 16: DG Optimisation Details for the 69-bus System with Composite Loads Models.

\section{CONCLUSION}

This paper has presented a developed software tool called PFADOT, for power flow analysis and optimisation of DG in radial distribution networks. The graphical user interface-based package, which used MATLAB platform, employed three objective functions formulated into a single optimisation problem and solved with fuzzy genetic algorithm. The purpose of the package is to enable distribution companies determine the optimal placement of DG in their networks in an efficient and economic manner.

The accuracy and reliability of the developed package was tested with several test radial systems and the results evaluated against the existing similar package, (Gözel et al., 2008), and were found to be impressive. The main advantage of this package is its exceptional high computational speed. The processing speed on a Pentium Dual-Core CPU E6500 at $2.93 \mathrm{GHz}$ and 2 GB RAM personal computer was less than 3 seconds for the 69-bus test system. This is against more than 40 seconds of (Gözel et al., 2008) for the same test system. On a whole, it was observed in the study that the optimal location generally varies with DG size.

\section{ACKNOWLEDGMENTS}

Many thanks to Gözel et al. (2008) for making VS\&OP an open source package; it really helped while developing PFADOT. Also, the technical advice offered while coding the algorithm by Mr. Syed Khaleel and Dr. M. Abdullah, both of Universiti Tenaga Nasional, Malaysia, and Mr. Omar Ceesay, a Master Student in the Computer and Communication Systems Engineering Department, UPM, are gratefully acknowledged. Finally, M. F. Akorede acknowledges with gratitude the financial support, in form of Graduate Research Fellowship, offered by the Universiti Putra Malaysia.

\section{APPENDIX}

The case study test systems line data are presented in this section.

Table A.1: 12 Bus System Line Data.

\begin{tabular}{ccccccc}
\hline $\begin{array}{c}\text { Line } \\
\text { No }\end{array}$ & $\begin{array}{c}\text { From } \\
\text { Bus }\end{array}$ & $\begin{array}{c}\text { To } \\
\text { Bus }\end{array}$ & $\begin{array}{c}\text { Voltage } \\
(\mathbf{k V})\end{array}$ & $\mathbf{R}(\mathbf{p u})$ & $\mathbf{X}(\mathbf{p u})$ & $\mathbf{1} / \mathbf{2} \mathbf{B}(\mathbf{p u})$ \\
\hline 1 & 1 & 2 & 11 & 0.000090 & 0.000038 & 0.000000 \\
2 & 2 & 3 & 11 & 0.000098 & 0.000041 & 0.000000 \\
3 & 3 & 4 & 11 & 0.000173 & 0.000072 & 0.000000 \\
4 & 4 & 5 & 11 & 0.000263 & 0.000110 & 0.000000 \\
5 & 5 & 6 & 11 & 0.000090 & 0.000038 & 0.000000 \\
6 & 6 & 7 & 11 & 0.000083 & 0.000034 & 0.000000 \\
7 & 7 & 8 & 11 & 0.000364 & 0.000100 & 0.000000 \\
8 & 8 & 9 & 11 & 0.000466 & 0.000132 & 0.000000 \\
9 & 9 & 10 & 11 & 0.000239 & 0.000068 & 0.000000 \\
10 & 10 & 11 & 11 & 0.000125 & 0.000035 & 0.000000 \\
11 & 11 & 12 & 11 & 0.000102 & 0.000029 & 0.000000 \\
\hline
\end{tabular}

Table A.2: 30 Bus System Line Data.

\begin{tabular}{ccccccc}
\hline $\begin{array}{c}\text { Line } \\
\text { No }\end{array}$ & $\begin{array}{c}\text { From } \\
\text { Bus }\end{array}$ & $\begin{array}{c}\text { To } \\
\text { Bus }\end{array}$ & $\begin{array}{c}\text { Voltage } \\
(\mathbf{k V})\end{array}$ & $\mathbf{R}(\mathbf{p u})$ & $\mathbf{X}(\mathbf{p u})$ & $\mathbf{1} / \mathbf{2} \mathbf{B}(\mathbf{p u})$ \\
\hline 1 & 1 & 2 & 11 & 0.096700 & 0.039700 & 0.000000 \\
2 & 2 & 3 & 11 & 0.088600 & 0.036400 & 0.000000 \\
3 & 3 & 4 & 11 & 0.135900 & 0.037700 & 0.000000 \\
4 & 4 & 5 & 11 & 0.123600 & 0.034300 & 0.000000 \\
5 & 5 & 6 & 11 & 0.123600 & 0.034300 & 0.000000 \\
6 & 6 & 7 & 11 & 0.259800 & 0.044600 & 0.000000 \\
7 & 7 & 8 & 11 & 0.173200 & 0.029800 & 0.000000 \\
8 & 8 & 9 & 11 & 0.259800 & 0.044600 & 0.000000 \\
9 & 9 & 10 & 11 & 0.173200 & 0.029800 & 0.000000 \\
10 & 10 & 11 & 11 & 0.108300 & 0.018600 & 0.000000 \\
11 & 11 & 12 & 11 & 0.086600 & 0.014900 & 0.000000 \\
12 & 3 & 13 & 11 & 0.129900 & 0.022300 & 0.000000 \\
13 & 13 & 14 & 11 & 0.173200 & 0.029800 & 0.000000 \\
14 & 14 & 15 & 11 & 0.086600 & 0.014900 & 0.000000 \\
15 & 15 & 16 & 11 & 0.043300 & 0.007400 & 0.000000 \\
16 & 6 & 17 & 11 & 0.148300 & 0.041200 & 0.000000 \\
17 & 17 & 18 & 11 & 0.135900 & 0.037700 & 0.000000 \\
18 & 18 & 19 & 11 & 0.171800 & 0.039100 & 0.000000 \\
19 & 19 & 20 & 11 & 0.156200 & 0.035500 & 0.000000 \\
20 & 20 & 21 & 11 & 0.156200 & 0.035500 & 0.000000 \\
21 & 21 & 22 & 11 & 0.216500 & 0.037200 & 0.000000 \\
22 & 22 & 23 & 11 & 0.216500 & 0.037200 & 0.000000 \\
23 & 23 & 24 & 11 & 0.259800 & 0.044600 & 0.000000 \\
24 & 24 & 25 & 11 & 0.173200 & 0.029800 & 0.000000 \\
25 & 25 & 26 & 11 & 0.108300 & 0.018600 & 0.000000 \\
26 & 26 & 27 & 11 & 0.086600 & 0.014900 & 0.000000 \\
27 & 7 & 28 & 11 & 0.129900 & 0.022300 & 0.000000 \\
28 & 28 & 29 & 11 & 0.129900 & 0.022300 & 0.000000 \\
29 & 29 & 30 & 11 & 0.129900 & 0.022300 & 0.000000 \\
\hline & & & & & & \\
\end{tabular}


Table A.3: 69 Bus System Line Data.

\begin{tabular}{|c|c|c|c|c|c|c|}
\hline $\begin{array}{c}\text { Line } \\
\text { No }\end{array}$ & $\begin{array}{c}\text { From } \\
\text { Bus }\end{array}$ & $\begin{array}{c}\text { To } \\
\text { Bus }\end{array}$ & $\begin{array}{c}\text { Voltage } \\
(\mathrm{kV})\end{array}$ & $\mathbf{R}(\mathbf{p u})$ & $\mathbf{X}(\mathbf{p u})$ & $1 / 2$ B (pu) \\
\hline 1 & 1 & 2 & 12.66 & 0.000300 & 0.000700 & 0.000000 \\
\hline 2 & 2 & 3 & 12.66 & 0.000300 & 0.000700 & 0.000000 \\
\hline 3 & 3 & 4 & 12.66 & 0.000900 & 0.002200 & 0.000000 \\
\hline 4 & 4 & 5 & 12.66 & 0.015700 & 0.018300 & 0.000000 \\
\hline 5 & 5 & 6 & 12.66 & 0.228400 & 0.116300 & 0.000000 \\
\hline 6 & 6 & 7 & 12.66 & 0.237800 & 0.121100 & 0.000000 \\
\hline 7 & 7 & 8 & 12.66 & 0.057500 & 0.029300 & 0.000000 \\
\hline 8 & 8 & 9 & 12.66 & 0.030800 & 0.015700 & 0.000000 \\
\hline 9 & 9 & 10 & 12.66 & 0.511000 & 0.168900 & 0.000000 \\
\hline 10 & 10 & 11 & 12.66 & 0.116800 & 0.038600 & 0.000000 \\
\hline 11 & 11 & 12 & 12.66 & 0.443800 & 0.146700 & 0.000000 \\
\hline 12 & 12 & 13 & 12.66 & 0.642600 & 0.212100 & 0.000000 \\
\hline 13 & 13 & 14 & 12.66 & 0.651400 & 0.215200 & 0.000000 \\
\hline 14 & 14 & 15 & 12.66 & 0.660100 & 0.218100 & 0.000000 \\
\hline 15 & 15 & 16 & 12.66 & 0.122700 & 0.040600 & 0.000000 \\
\hline 16 & 16 & 17 & 12.66 & 0.233600 & 0.077200 & 0.000000 \\
\hline 17 & 17 & 18 & 12.66 & 0.002900 & 0.001000 & 0.000000 \\
\hline 18 & 18 & 19 & 12.66 & 0.204400 & 0.067600 & 0.000000 \\
\hline 19 & 19 & 20 & 12.66 & 0.131400 & 0.043400 & 0.000000 \\
\hline 20 & 20 & 21 & 12.66 & 0.213100 & 0.070400 & 0.000000 \\
\hline 21 & 21 & 22 & 12.66 & 0.008700 & 0.002900 & 0.000000 \\
\hline 22 & 22 & 23 & 12.66 & 0.099300 & 0.032800 & 0.000000 \\
\hline 23 & 23 & 24 & 12.66 & 0.216100 & 0.071400 & 0.000000 \\
\hline 24 & 24 & 25 & 12.66 & 0.467200 & 0.154400 & 0.000000 \\
\hline 25 & 25 & 26 & 12.66 & 0.192700 & 0.063700 & 0.000000 \\
\hline 26 & 26 & 27 & 12.66 & 0.108100 & 0.035700 & 0.000000 \\
\hline 27 & 3 & 28 & 12.66 & 0.002700 & 0.006700 & 0.000000 \\
\hline 28 & 28 & 29 & 12.66 & 0.039900 & 0.097600 & 0.000000 \\
\hline 29 & 29 & 30 & 12.66 & 0.248200 & 0.082000 & 0.000000 \\
\hline 30 & 30 & 31 & 12.66 & 0.043800 & 0.014500 & 0.000000 \\
\hline 31 & 31 & 32 & 12.66 & 0.219000 & 0.072400 & 0.000000 \\
\hline 32 & 32 & 33 & 12.66 & 0.523500 & 0.175700 & 0.000000 \\
\hline 33 & 33 & 34 & 12.66 & 1.065600 & 0.352300 & 0.000000 \\
\hline 34 & 34 & 35 & 12.66 & 0.919600 & 0.304000 & 0.000000 \\
\hline 35 & 3 & 36 & 12.66 & 0.002700 & 0.006700 & 0.000000 \\
\hline 36 & 36 & 37 & 12.66 & 0.039900 & 0.097600 & 0.000000 \\
\hline 37 & 37 & 38 & 12.66 & 0.065700 & 0.076700 & 0.000000 \\
\hline 38 & 38 & 39 & 12.66 & 0.019000 & 0.022100 & 0.000000 \\
\hline 39 & 39 & 40 & 12.66 & 0.001100 & 0.001300 & 0.000000 \\
\hline 40 & 40 & 41 & 12.66 & 0.454400 & 0.530900 & 0.000000 \\
\hline 41 & 41 & 42 & 12.66 & 0.193400 & 0.226000 & 0.000000 \\
\hline 42 & 42 & 43 & 12.66 & 0.025600 & 0.029800 & 0.000000 \\
\hline 43 & 43 & 44 & 12.66 & 0.005700 & 0.007200 & 0.000000 \\
\hline 44 & 44 & 45 & 12.66 & 0.067900 & 0.085700 & 0.000000 \\
\hline 45 & 45 & 46 & 12.66 & 0.000600 & 0.000700 & 0.000000 \\
\hline 46 & 4 & 47 & 12.66 & 0.002100 & 0.005200 & 0.000000 \\
\hline 47 & 47 & 48 & 12.66 & 0.053100 & 0.130000 & 0.000000 \\
\hline 48 & 48 & 49 & 12.66 & 0.180800 & 0.442400 & 0.000000 \\
\hline 49 & 49 & 50 & 12.66 & 0.051300 & 0.125500 & 0.000000 \\
\hline 50 & 8 & 51 & 12.66 & 0.057900 & 0.029500 & 0.000000 \\
\hline 51 & 51 & 52 & 12.66 & 0.207100 & 0.069500 & 0.000000 \\
\hline 52 & 9 & 53 & 12.66 & 0.108600 & 0.055300 & 0.000000 \\
\hline 53 & 53 & 54 & 12.66 & 0.126700 & 0.064500 & 0.000000 \\
\hline 54 & 54 & 55 & 12.66 & 0.177300 & 0.090300 & 0.000000 \\
\hline 55 & 55 & 56 & 12.66 & 0.175500 & 0.089400 & 0.000000 \\
\hline 56 & 56 & 57 & 12.66 & 0.992000 & 0.333000 & 0.000000 \\
\hline 57 & 57 & 58 & 12.66 & 0.489000 & 0.164100 & 0.000000 \\
\hline 58 & 58 & 59 & 12.66 & 0.189800 & 0.062800 & 0.000000 \\
\hline 59 & 59 & 60 & 12.66 & 0.240900 & 0.073100 & 0.000000 \\
\hline 60 & 60 & 61 & 12.66 & 0.316600 & 0.161300 & 0.000000 \\
\hline 61 & 61 & 62 & 12.66 & 0.060800 & 0.030900 & 0.000000 \\
\hline 62 & 62 & 63 & 12.66 & 0.090500 & 0.046000 & 0.000000 \\
\hline 63 & 63 & 64 & 12.66 & 0.443300 & 0.225800 & 0.000000 \\
\hline 64 & 64 & 65 & 12.66 & 0.649500 & 0.330800 & 0.000000 \\
\hline 65 & 11 & 66 & 12.66 & 0.125500 & 0.038100 & 0.000000 \\
\hline 66 & 66 & 67 & 12.66 & 0.002900 & 0.000900 & 0.000000 \\
\hline 67 & 12 & 68 & 12.66 & 0.461300 & 0.152500 & 0.000000 \\
\hline 68 & 68 & 69 & 12.66 & 0.002900 & 0.001000 & 0.000000 \\
\hline
\end{tabular}

\section{REFERENCES}

Acharya, N.; P. Mahat and N. Mithulananthan. (2006). An analytical approach for DG allocation in primary distribution network. Int. J. of Elect. Power and Energy Syst. 28(10): 669-678.

Akorede, M. F.; E. Pouresmaeil, H. Hazim, I. Aris and M. Z. Ab-Kadir. (2014). Optimal Placement of NonSite Specific DG for Voltage Profile Improvement and Energy Savings in Radial Distribution Networks. Advances in Electrical and Electronic Engineering. 12 (5), 392-406.

California (2010). California Distributed Energy Resources Guide, California Energy Commission, retrieved March 15, 2010 from www.energy.ca.gov/distgen/.

CIRED (1999). Dispersed Generation; Preliminary Report of CIRED (International Conference of Electricity Distribution), Working Group WG04, Brussels, Belgium.

Gözel, T.; U. Eminoglu and M. H. Hocaoglu. (2008). A tool for voltage stability and optimization (VS\&OP) in radial distribution systems using matlab graphical user interface (GUI). Simulation Modelling Practice and Theory 16(5): 505-518.

Gözel, T. and Hocaoglu, M. H. (2009). An analytical method for the sizing and siting of distributed generators in radial systems. Elect. Power Syst. Res. 79(6): 912-918.

Griffin, T.; K. Tomsovic, D. Secrest and A. Law. (2000). Placement of dispersed generation systems for reduced losses. Proceedings of the 33rd Annual Hawaii Int. Conf. on Syst. Sci. 1-9.

GUIDE (2010b). GUIDE: Getting Started, MATLAB R2010b Documentation retrieved January 2011 from http://www.mathworks.com.

Hanselman, D. and Littlefield, B. (2005). Mastering Matlab 7. New Jersey, USA, Pearson Education, Inc., Prentice Hall.

Jiang, J. and Klein, G. (2000). Software development risks to project effectiveness. J. of Syst. and Software 52(1): 3-10.

Kashem, M. A.; A. D. T. Le, M. Negnevitsky and G. Ledwich. (2006). Distributed generation for minimization of power losses in distribution systems. IEEE Power Eng. Soc. Gen. Meeting, Montreal, Que. 1-8.

Khalesi, N.; N. Rezaei and M. R. Haghifam. (2011). DG allocation with application of dynamic programming for loss reduction and reliability improvement. Int. J. of Elect. Power \& Energy Syst. 33(2): 288-295

Khan, H. and Choudhry, M. (2010). Implementation of Distributed Generation (IDG) algorithm for performance enhancement of distribution feeder under extreme load growth. Int. J. of Elect. Power \& Energy Syst. 32(9): 985997.

Kim, J. O.; S. K. Park, K. W. Park and C. Singh. (1998). Dispersed generation planning using improved Hereford Ranch algorithm. Elect. Power Syst. Res. 47(1): 4755.

Milano, F. (2005). An open source power system analysis toolbox. IEEE Trans. on Power Syst. 20(3): 11991206.

Mithulananthan, N.; O. Than and L. V. Phu. (2004). Distributed Generator Placement in Power Distribution 
System Using Genetic Algorithm to Reduce Losses. Thammasat Int. J. of Sci. and Tech. 9(3): 55-62.

Ochoa, L. F. and Harrison, G. P. (2010). Using AC Optimal Power Flow for DG planning and optimisation. IEEE Power and Energy Soc. Gen. Meeting.

Pai, M. (1979). Computer techniques in power system analysis, Tata McGraw-Hill New Delhi/India.

Saadat, H. (2002). Power System Analysis. McGrawHill Higher Education (ISBN 0-07-284-869-3).

Singh, D.; D. Singh and K. S. Verma. (2007). GA based Optimal Sizing \& Placement of Distributed Generation for Loss Minimization. Int. J. of Intelligent Syst. and Tech. 2(4): 263-269.

Singh, R. and Goswami, S. (2009). Optimum siting and sizing of distributed generations in radial and networked systems. Electr. Power Compt. and Syst. 37(2): 127-145.
Srinivas, M. and Patnaik, L. M. (1994). Genetic algorithms: A survey. Computer 27(6): 17-26.

User (2011). User interface and interaction design, Retrieved January 2016 from http://en.wikipedia.org/wiki/Graphical_user_interface.

Verbic, G.; M. Pantos and Gubina, F. (2006). On voltage collapse and apparent-power losses. Elect. Power Syst. Res. 76(9-10): 760-767.

Vu, V. T.; D. D. Van and R. Belmans. (2006). Penetration level of distributed energy resources with antiislanding criteria and secure operation of power system. IEEE Power Eng. Soc. Gen. Meeting, Montreal, Que. 1-7.

Wang, C. and Nehrir M. H. (2004). Analytical approaches for optimal placement of distributed generation sources in power systems. IEEE Trans. on Power Syst. 19(4): 2068-2076. 